\title{
CONTRIBUIÇÕES TEÓRICAS E METODOLÓGICAS DA HISTÓRIA CONCEITUAL PARA OS ESTUDOS DO LAZER ${ }^{1}$
}

Recebido em: 26/12/2017

Aceito em: 19/10/2018

\author{
Flávia da Cruz Santos ${ }^{2}$ \\ Universidade Federal de Juiz de Fora \\ Juiz de Fora - MG - Brasil
}

\begin{abstract}
RESUMO: Considerando que a definição de lazer ainda é uma questão para os estudiosos que se dedicam a este tema, este trabalho intenciona apontar a proposta teórico-metodológica da história dos conceitos, do historiador alemão Reinhart Koselleck (2006), como possibilidade teórica e metodológica para a melhor elaboração conceitual desse fenômeno. Koselleck (2006) evidencia a necessidade de diferenciação entre um conceito científico e um conceito empírico, e indica os procedimentos metodológicos para a construção de cada um deles. Sua proposta consiste em reconstituir uma mostra dos usos do conceito, realizados pelos atores de um determinado contexto, o que inclui a palavra que o nomeia, mas a ultrapassa, incluindo seu significado histórico. O que nos permitirá compreender o lazer ao longo do tempo e, assim, defini-lo melhor nas investigações contemporâneas que realizamos do passado. Nos permitirá, ainda, verificar a capacidade heurística do atual conceito de lazer, analisando o seu alcance temporal e a validade de suas balizas.
\end{abstract}

PALAVRAS CHAVE: História do Lazer. História Conceitual. Teoria da História.

\section{THEORETICAL AND METHODOLOGICAL CONTRIBUTIONS OF THE CONCEPTUAL HISTORY FOR LEISURE STUDIES}

ABSTRACT: Considering that the conceptual definition of leisure is still a question for scholars dedicated to this subject, this text intends to point out the theoreticalmethodological proposal of Reinhart Koselleck (2006) of the history of concepts as a theoretical and methodological possibility for the best conceptual elaboration of this phenomenon. Koselleck (2006) highlights the need to differentiate between a scientific concept and an empirical concept, and indicates the methodological procedures for its construction. He proposes the reconstitution of a sample of the uses of the concept by the actors of a given context, which includes the word that names it, but surpasses it, including its historical meaning. This will allow us to understand leisure over time and this better define it in our contemporary investigations of the past. It will also allow us

\footnotetext{
${ }^{1}$ Pesquisa financiada pela Capes.

${ }^{2}$ Doutora em Estudos do Lazer pela Universidade Federal de Minas Gerais, Mestre em Educação Física pela Universidade Estadual de Campinas, Licenciada e Bacharel em Educação Física pela Universidade Federal de Minas Gerais. Professora da Universidade Federal de Juiz de Fora.
} 
to verify the heuristic capacity of the current leisure concept, analyzing its temporal reach and the validity of its beacons.

KEYWORDS: History of leisure. Conceptual history. Teory of history.

\section{Introdução}

Há vários motivos que não apenas justificam, mas tornam necessário o desenvolvimento de pesquisas empíricas sobre a história do conceito de lazer no Brasil. Um deles, é o fato de não sabermos exatamente o alcance deste conceito, ou seja, não sabermos como e a partir de quando podemos usá-lo. É o que indicam, desde algum tempo, vários pesquisadores do campo de estudos do lazer (REIS, CAVICHIOLLI, STAREPRAVO, 2009; MELO, 2009; MELO, 2011; MELO, 2013; DIAS, 2009; DIAS, 2013; DIAS, 2014; SANTOS, 2009; SANTOS, 2017).

Dito de outro modo, não há clareza quanto aos marcadores que devem ser usados para definir se uma prática pode ou não ser denominada de lazer, se pode ou não ser englobada por este conceito. Tão pouco há um entendimento minimamente consensual sobre até onde podemos recuar no tempo usando o conceito de lazer. Tais determinações, quando necessárias, tem sido feitas a partir da reprodução de um modelo europeu, ou da construção de inferências lógicas, o que demonstra uma certa compreensão do fazer historiográfico e da própria história, como se esta última fosse apenas avanços e linearidade.

Nas páginas que seguem, explicarei mais detidamente essa compreensão do que tem se passado nos estudos do lazer quando o tema é a história de tal fenômeno e o seu conceito, bem como suas implicações para o campo da pesquisa. Discutirei as noções de conceito que tem informado tais compreensões, na tentativa não apenas de denunciar certa confusão, mas, principalmente, de à luz das contribuições teóricas e metodológicas 
da história conceitual do historiador alemão Reinhart Koselleck (2006), evidenciar a necessidade de melhor elucidar o que seja um conceito. Em seguida, indicarei as possíveis contribuições da história dos conceitos para a elaboração conceitual do lazer, e melhor compreensão deste fato social.

A história conceitual apresenta contribuições aos estudos do lazer, de modo geral, pois pode possibilitar a melhor compreensão conceitual deste fenômeno ao longo do tempo, permitindo saber se podemos ou não usar o conceito atual, com seus significados, quando nos referirmos a um determinado passado, evitando, assim, anacronismos. Do mesmo modo, saberemos também se os conceitos do passado mantém seus significados no presente, ou se eles passaram por alguma alteração. Tratase da historicização dos conceitos, da compreensão da semântica histórica dos mesmos.

Para os estudos históricos do lazer, há ainda outras contribuições, teóricas e metodológicas, mais específicas. Koselleck (2006) indica a insuficiência da etimologia das palavras, bem como do apego às mesmas na identificação e compreensão de um fenômeno e elaboração de seu conceito. Apresenta caminhos metodológicos que indicam a busca pelo fato social, pelo fenômeno, e não apenas pelo símbolo linguístico usado para nomeá-lo.

Nesse ponto, une-se a Koselleck (2006) o historiador Marc Bloch (2001) de quem também tomarei algumas contribuições. Pois ainda que sem saber, e em momento anterior, Bloch (2001) dialoga com a história conceitual, indicando que as palavras e os fenômenos a que elas nomeiam se relacionam de diferentes modos. Esses modos estão diretamente ligados ao processo histórico de construção do fenômeno, que precisa ser compreendido para que seu conceito possa ser articulado. 
O princípio metodológico básico, indicado pela história conceitual é a tradução de significados lexicais em uso no passado para a nossa compreensão contemporânea. Koselleck (2006) sugere que os significados dos conceitos devem ser investigados ao longo de uma sequência temporal, focalizando a sua duração ou transformação sob uma perspectiva diacrônica. Os antônimos e neologismos também precisam ser investigados, assim como suas intersecções. Apresentarei a seguir, alguns elementos do pensamento desse estudioso que podem oferecer contribuições aos estudos do lazer de modo geral e, mais especificamente, aos estudos históricos do lazer.

\section{O Conceito de Lazer nos Estudos do Lazer: Desfazendo o Imbróglio a Partir das Contribuições da História Conceitual}

O que os estudiosos brasileiros do lazer tem feito é considerar, arbitrariamente, como sendo lazer as práticas de divertimento ocorridas a partir da industrialização (MELO, ALVES JUNIOR, 2003; MASCARENHAS, 2005; MARCASSA, 2002; MARCELLINO, 1983). Digo arbitrariamente, porque não há argumentos empíricos que justifiquem tal procedimento, tal delineamento do objeto desse campo de estudos. O que há são apenas argumentos construídos a partir de um encadeamento lógico de ideias, e/ou a reprodução de um modelo europeu de compreensão de tal fenômeno, cujo principal representante é Joffre Dumazedier (1999). Mas será que podemos pensar na história de tal modo, como um encadeamento lógico de acontecimentos? Podemos reproduzir um mesmo modelo de desenvolvimento histórico, em realidades tão diversas?

A industrialização forjou mudanças econômicas, novos hábitos culturais, inaugurou modos de vida. Esse novo contexto levou à perda de costumes e tradições, 
que não ocorreu sem resistências e permanências. $\mathrm{O}$ investimento na mudança dos padrões culturais de comportamento, no forjar de novos hábitos marca a modernidade, que é entendida como um momento de ruptura entre o velho e o novo. Todos os hábitos deviam mudar para se adequar ao novo modo de vida. Daí vem a tão propalada tese do sociólogo francês Joffre Dumazedier, construída no contexto francês e a partir dele, compartilhada por outros tantos estudiosos do tema no Brasil e no exterior, de que "o lazer possui traços específicos, característicos da civilização nascida da Revolução Industrial" (1999, p. 26).

As características do contexto industrial reúnem, segundo Dumazedier, os elementos geradores e definidores desse novo fenômeno, necessários à sua existência. $\mathrm{O}$ principal deles, uma premissa clássica dos estudos do lazer, é a demarcação rígida dos tempos, que Edward Palmer Thompson (1988, p. 297) chamou, no caso inglês, de “disciplina do tempo", a demarcação clara entre o tempo de trabalho e o tempo livre de trabalho, no qual o lazer acontece. Esse argumento permeia os estudos que tem como tema o lazer no Brasil, mesmo que o seu surgimento não seja o tema central, e é compartilhado por autores que guardam muitas diferenças entre as compreensões de lazer que possuem.

Houve mudanças, grandes mudanças, do período pré-industrial para o período industrial. Dentre elas, estão as mudanças nos hábitos de divertimento. Mas tais mudanças implicam necessariamente na supressão de um formato de diversão e na inauguração de outro, totalmente novo, na emergência de um novo fenômeno? E no Brasil, mais especificamente, como esse processo se deu? Essa questão nos leva a considerar as especificidades históricas de nosso país, pois essa teoria da 
descontinuidade do lazer, como chamou Peter Burke (1995), apesar de muito aceita no Brasil, não foi construída a partir de sua realidade.

Não houve revolução industrial no Brasil, daí o fato de não poder haver uma civilização dela, nascida entre nós brasileiros. Não é que não tenhamos sentido os efeitos de tal revolução, ela repercutiu entre nós, mas não constituímos uma sociedade dela nascida. Entre nós, o processo se deu de outro modo e, portanto, suas consequências também são diferentes.

A existência de rigidez na demarcação dos tempos sociais, na separação do tempo de trabalho do tempo de lazer no período industrial, tida como fundamental para a existência do lazer, tem sido questionada por historiadores que não pertencem ao chamado campo de estudos do lazer, e que se dedicaram a investigar empiricamente o cotidiano de trabalhadores brasileiros no final do século XIX e início do XX.

Esse é o caso de Sidney Chalhoub e Uassyr Siqueria. "O ideal burguês de separação rígida entre lazer e trabalho não tem significado algum: trabalho e diversão estão associados no cotidiano e não são regidos por horários fixos", é o que nos diz Chalhoub (2001, p. 258) ao analisar o cotidiano de trabalhadores na cidade do Rio de Janeiro da belle époque. E Siqueira, ao analisar o dia-a-dia dos trabalhadores paulistanos entre 1890 e 1920, conclui na mesma direção: "tempo de trabalho e tempo de lazer não eram rigidamente demarcados, se misturando no cotidiano dos trabalhadores" (SIQUEIRA, 2008, p. 20).

Por outro lado, tem sido questionada também a inexistência de separação entre os tempos sociais em sociedades pré-industriais. Cleber Dias (2013, p. 32), baseado em vários estudos, afirma que: 
Ao longo de todo o período colonial, havia trabalhadores que alienavam sua força de trabalho por um salário em nome da sobrevivência, submetendo-se a uma jornada com duração predeterminada. Isso implica, em contrapartida, em tempo socialmente demarcado para o não-trabalho que seria então ocupado nas tabernas, nos teatros, nas apresentações circenses, nas procissões e festas religiosas, em divertimentos domésticos como baralhos ou leituras individuais, nos saraus, nas serestas, nos batuques, nos lundus, nos jogos de argolinha, nas cavalhadas ou em toda uma enorme gama de práticas e atividades que se desenvolviam nessa esfera social.

Essa breve, e já cansativa - devido à sua repetição nos estudos - descrição de como tem se dado a construção do conceito de lazer nos chamados estudos do lazer no Brasil, nos permite perceber que o mesmo não foi elaborado a partir de pesquisas históricas empíricas, que ele não é uma "categoria nativa"33. Ou dito de outro modo, não foi a partir de investigações históricas que se chegou ao conceito de lazer, ou aos elementos balizadores de sua definição. Ele não foi encontrado nas fontes, nos vestígios do passado, da maneira que tem sido apresentado, simplesmente porque as investigações capazes de fazê-lo não foram realizadas.

O conceito de lazer com o qual temos operado em nossas investigações, ao contrário, é uma elaboração científica realizada por uma comunidade acadêmica que vem, cada vez mais, se organizando e especializando em torno dos estudos de tal tema. O que parece estar acontecendo desde a década de $1970^{4}$, é a construção pela academia de um instrumento heurístico, uma categoria de análise que tem permitido aos pesquisadores acessar suas realidades de estudo.

O problema tem sido o alcance temporal de tal categoria, pois como a industrialização tem sido o marco a partir do qual o conceito de lazer é usado, os tempos

\footnotetext{
${ }^{3}$ Categoria nativa ou compreensão nativa são noções caras à Antropologia. Para mais informações ver Araújo (2011) e Castro (2002).

${ }^{4}$ A década de 1970, é apontada como sendo o momento em que tem início a conformação de um campo de estudos do lazer no Brasil (MELO, 2013; GOMES, MELO, 2003). Desde então, identifico o movimento de construção de um conceito de lazer como instrumento heurístico.
} 
que antecedem tal acontecimento ficam descobertos, sem serem estudados a partir da noção de lazer ${ }^{5}$. Outro problema é que quando colocado à prova por estudos empíricos, mesmo aqueles que tem como contextos sociedades industriais, tal conceito, com suas balizas e elementos definidores, tem se mostrado frágil e pouco útil, como vimos.

Apesar de ser um conceito científico, e não uma categoria nativa, há um apego ao símbolo linguístico utilizado nos documentos históricos, o entendimento de que só podemos falar de lazer se essa palavra estiver presente nas fontes. O que é uma contradição, visto que os conceitos científicos são elaborados na contemporaneidade, justamente para traduzir um uso linguístico antigo (KOSELLECK, 2006, p. 116). Deste modo, o impedimento ou a pertinência do uso do conceito de lazer para analisar contextos passados, deveria se dar a partir do seu significado, do seu conteúdo, e não do seu nome. Essa postura, de apego à palavra, tem feito com que a capacidade explicativa e o alcance do conceito de lazer sejam drasticamente reduzidos. O que está se passando, é a adoção, de forma confusa e sem explicação, de uma categoria analítica como se fosse categoria nativa. Sobre tal postura Marc Bloch adverte, e indica um procedimento metodológico:

\begin{abstract}
Estimar que a nomenclatura dos documentos possa bastar completamente para fixar a nossa seria o mesmo, em suma, que admitir que nos fornecem a análise toda pronta. A história, nesse caso, não teria muito a fazer. Felizmente, para nossa satisfação, não é nada disso. Eis porque somos obrigados a procurar em outro lugar nossas grandes estruturas de classificação (BLOCH, 2001, p. 142).
\end{abstract}

Por mais que possamos encontrar o termo lazer em documentos históricos, e que possamos captar seu conteúdo, ou seja, os usos que os sujeitos de um determinado

\footnotetext{
${ }^{5}$ Há pelo menos duas pesquisas que colocaram tal noção à prova, e que concluíram ter havido lazer no Brasil pré-industrial, quando o uso dessa palavra ainda não se dava de modo generalizado. São elas SANTOS (2017) e DIAS (2013). Nesses casos, o que os pesquisadores levaram em conta, principalmente, foi o significado do que as pessoas faziam, e não apenas o modo como denominavam o que faziam.
} 
tempo lhe conferiam, seus sentidos e significados, seu conceito tem sido determinado muito menos por isso, e muito mais por elaborações teóricas. Não foi a partir de pesquisas empíricas que fixou-se a ideia de que o lazer é um fenômeno moderno, entendida a modernidade aí, como sinônimo de industrialização.

Também não foi a partir de pesquisas dessa natureza, que construiu-se o entendimento de que o lazer acontece e é vivido pelas pessoas, em um tempo apartado do tempo de trabalho. As pesquisas necessárias para a construção de tais compreensões simplesmente não foram ainda realizadas. E aqui reside um problema, pois por mais evidentes que tais relações possam parecer, elas não podem ser postuladas previamente na investigação histórica (BLOCH, 2001, p. 151).

Percebemos, portanto, que o conceito de lazer no Brasil, construído para ajudar na análise, como uma categoria analítica, tem acabado por dispensar o trabalho de analisar, na medida em que da como certa a inexistência do fenômeno em contextos nunca investigados sob sua perspectiva. O conceito tem limitado as pesquisas, restringido seus recortes temporais e geográficos, impedido que investigações sejam realizadas, e que a capacidade explicativa do próprio conceito seja colocada à prova.

Sem que qualquer pesquisa tenha sido realizada, convencionou-se que no Brasil pré-industrial não havia lazer, assim como também convencionou-se que esse fato social só existe em sociedades urbanas e que ele acontece, na vida cotidiana, em um tempo totalmente apartado do tempo de trabalho. A análise, assim, é dada como pronta antes de ser realizada. Ao invés de o conceito dizer de uma dada realidade, é a realidade que tem precisado se adequar ao conceito.

Esses e outros marcadores do conceito de lazer, que são definidores dos modos de compreendê-lo no Brasil, foram construídos, por uma comunidade científica que tem 
a ele se dedicado como objeto de estudos. O movimento tem sido o de partir desse conceito científico, de nortear as pesquisas, definir seu recorte temporal, geográfico, as práticas estudadas, a partir dele. Mesmo quando as pesquisas tratam do passado, há a preocupação por parte de seus autores, de apresentar um conceito de lazer aprioristicamente, antes mesmo de visitar as fontes. Conceito esse que, portanto, é contemporâneo e pode não dizer do passado estudado.

Por tudo isso, precisamos nos atentar para as diferenças entre um conceito analítico ou científico, e um conceito empírico ou nativo, aquele que pode ser encontrado nas fontes. Um conceito analítico é elaborado cientificamente, por uma comunidade acadêmica, e serve como acesso tanto a realidades em que ele estava linguisticamente articulado, quanto a realidades em que ele não estava linguisticamente articulado, e, deste modo, pode não ser nomeadamente encontrado nas fontes (KOSELLECK, 2006; BLOCH, 2001).

Um conceito empírico, no entanto, nos foi herdado da tradição, ele se refere a um fato social que foi linguisticamente articulado no passado e, por isso, pode ser nomeadamente encontrado nos vestígios históricos (KOSELLECK, 2006).

O fato é que no caso do lazer, como tentei demonstrar até aqui, há uma confusão entre esses dois tipos de conceito, o uso indiscriminado dos mesmos. Isso tem gerado limitações às nossas pesquisas, já que o conceito de lazer tal qual tem sido adotado, nos permite estudar apenas um passado muito recente, aquele subsequente à industrialização brasileira, e, as vezes, ele não tem dito da realidade estudada, já que os elementos que o definem nem sempre são encontrados.

Uma melhor compreensão da história do lazer, é fundamental para a compreensão e consequente elaboração de seu conceito. Elaboração essa que não se dá a 
partir de teorias, mas, ao contrário, a partir da empiria, do trabalho com os documentos históricos. Na história, é a empiria que deve fomentar a teoria, e não o contrário, como tem acontecido. Por mais óbvias que certas relações possam parecer, elas não podem ser postuladas sem a realização de investigações, sob o risco de adaptarmos a realidade estudada às nossas classificações e construções teóricas, quando a finalidade última de toda ciência é exatamente o contrário, adaptar suas classificações às realidades estudadas (BLOCH, 2001, p. 153) e, assim, aperfeiçoar cada vez mais seus instrumentos heurísticos.

Nesse sentido, o método da história conceitual de Reinhart Koselleck (2006) tem muito a nos oferecer. Ele nos permite conhecer não apenas os usos linguísticos, mas os seus conteúdos, ou seja, aquilo que é nomeado pelas palavras, os significados a elas atribuídos por seus usuários. Que significados os protagonistas de um determinado tempo e lugar davam à palavra lazer, do que diziam quando a evocavam? Outras palavras já foram usadas para denominar este mesmo fato social?

Deste modo, apresentarei a seguir a proposta teórico-metodológica da história conceitual de Koselleck (2006), evidenciando suas possíveis contribuições não apenas para a história do lazer no Brasil e sua formulação conceitual, mas para os estudos do lazer como um todo.

\section{Possíveis Subsídios Teórico-Metodológicos da História Conceitual}

A proposta teórico-metodológica do historiador Koselleck (2006) pode contribuir para o desenvolvimento mais consistente dos estudos do lazer e para o melhor delineamento de seu conceito, pois a finalidade de tal proposta é captar e compreender o significado de um conceito e as alterações pelas quais ele passou ao longo do tempo. 
Inicialmente, é necessário demarcar a diferenciação que o método faz entre palavra e conceito, o que já se constitui em uma primeira contribuição metodológica para os estudos do lazer, já que ajuda a compreender os sentidos de um conceito e os modos de delimitá-lo. De acordo com Koselleck (2006, p. 109), tanto uma palavra quanto um conceito, podem possuir diferentes significados, no entanto, cada significado de uma palavra é empregado de modo particular, de acordo com o contexto em que ela é usada; já os significados de um conceito estão sempre, todos, presentes quando ele é usado, não importa a situação de seu emprego, ele é sempre polissêmico. Assim, as palavras expressam os conceitos, mas não se confundem com eles.

Com essa diferenciação entre palavra e conceito, Koselleck (2006) demonstra a insuficiência da etimologia das palavras para a compreensão de um conceito, pois não se pode reduzir a história do fenômeno à história da palavra que o designa. Por isso, a etimologia da palavra lazer, e de qualquer outro símbolo linguístico do seu léxico semântico - divertimento, diversão, recreação ou passatempo, por exemplo -, não basta para dizer do significado do fato social ou para defini-lo conceitualmente.

Um termo pode perdurar por séculos e pode existir em contextos distintos, mas nem sempre da mesma forma. Os significados dos conceitos, por outro lado, quase sempre mudam ao longo do tempo, pois as mudanças de contexto podem implicar mudanças desses significados. Isso é a variação temporal dos conceitos, que confere a eles um caráter único, visto que seu significado é específico ao contexto de sua utilização (KOSELLECK, 2006).

Deste modo, para a história conceitual o uso da palavra é mais significativo para a compressão de seu significado do que sua etimologia, pois o significado etimológico de uma palavra pode ser o mesmo em toda uma comunidade linguística, mas seus usos, 
que podem lhe conferir significados outros, são diversos: "os significados das palavras são os usos, como as usamos na cotidianidade.” (SEBASTIÁN, 2013, p. 57).

Portanto, apesar de a palavra lazer estar presente no primeiro dicionário da língua portuguesa (BLUTEAU, 1716), do século XVIII, isso não significa que ela tenha sido usada no Brasil desde então. E ao longo do tempo em que esse uso tem se dado não sabemos se o seu conteúdo, ou seja, o que essa palavra designa, tem sido sempre a mesma coisa ou passou por alterações. Por outro lado, não sabemos também se já houve ou se há uma outra palavra que designasse o mesmo conteúdo que a palavra lazer designa, ou se houve algum conteúdo correlato ao lazer em tempos passados, ainda que denominado de outra forma ${ }^{6}$.

Antes mesmo de Koselleck elaborar a proposta da história conceitual, Marc Bloch (2001) já apresentava argumentos que indicavam a necessidade de investigarmos os fenômenos e suas mudanças, sem termos como elementos determinantes os seus nomes. "Uma palavra vale menos por sua etimologia do que pelo uso que dela é feito", disse Bloch (2001, p. 143), justamente por que uma palavra pode ser usada de diferentes formas em diferentes contextos e por diferentes sujeitos. Significados e estruturas de sentimentos podem ser a ela atribuídos de acordo com o grupo social, momento histórico e lugar em que ela é usada.

Bloch (2001, p. 136) ainda indica que podem existir diferentes formas de relacionamento entre o fenômeno social e o seu nome. Segundo esse historiador, a

\footnotetext{
${ }^{6} \mathrm{O}$ pesquisador Victor Melo tem operado em seus estudos com a noção de diversão, quando o contexto abordado é o Rio de Janeiro do século XIX. Alguns exemplos desses estudos são Melo (2010; 2011; 2013; 2015). No entanto, ele parte do atual conceito científico de lazer, com suas balizas e elementos definidores, em direção às fontes. Como esses elementos definidores não estavam totalmente presentes no contexto investigado, e o uso da palavra lazer pouco se dava, ele conclui pela inexistência de lazer e adota a categoria nativa, ou seja, aquela encontrada nomeadamente nas fontes. Por outro lado, os estudos de Santos (2017), que tem a São Paulo do XIX como contexto, e de Dias (2013), que se dedica à cidade do Rio de Janeiro no último quartel do século XVIII e décadas iniciais do século XIX, concluem pela existência de lazer, ainda que tal termo não fosse empregado ou seus usos fossem inexpressivos. Adiante retomarei mais detalhadamente estes dois últimos estudos.
} 
mudança do fenômeno nem sempre acarreta mudança paralela no seu nome, do mesmo modo, os nomes podem variar no tempo e no espaço sem que haja qualquer variação no fato social. Cada uma dessas formas de relacionamento fenômeno-palavra, indica diferentes modos de constituição do fato social e diz do seu conceito, dos modos como ele foi engendrado. Assim, compreender essas formas de relacionamento, os modos como elas se deram, é necessário para a compreensão e consequente articulação do conceito.

Sobre isso, Koselleck (2006, p. 114) traz um ponto fundamental para os estudos do lazer: "fatos cuja alteração se dá lentamente, a longo prazo, podem ser compreendidos por meio de expressões bastante variadas." O que nos indica que podemos compreender o lazer em tempos passados a partir de outras denominações, e que o início do uso sistemático da palavra lazer não é suficiente para indicar uma alteração no quadro social, a emergência de um fenômeno completamente novo.

Sabemos que a palavra lazer começa a ser utilizada de modo sistemático no Brasil a partir da década de 1970 , principalmente no meio acadêmico ${ }^{7}$, com sentidos mais ou menos homogêneos. Mas não conhecemos os primórdios do processo que culminou nesses usos, e tão pouco o processo de cunhagem da palavra lazer, ou seja, não sabemos se trata-se de uma transição conceitual que culminou na constituição de um novo fenômeno, ou se trata-se apenas de uma nova denominação para um fato social já existente.

Ao investigar a cidade do Rio de Janeiro no período 1779- 1838, Cleber Dias (2013) conclui que já nesse período o lazer estaria em processo de formação, e que depois de 1838 ele estaria devidamente formado, “em algumas circunstâncias, inclusive,

\footnotetext{
${ }^{7}$ Cf. MELO, 2013, p. 20. Enquanto a trajetória institucional de tal termo é conhecida nesse pequeno período, o termo que a população, nas suas diferentes camadas sociais, utilizava para denominar o mesmo fenômeno é desconhecido.
} 
até em pleno desenvolvimento, amadurecido, em condições, de todo modo, de se disseminar" (p. 18). Ainda que o termo lazer não fosse de uso corrente neste contexto. Portanto, segundo tal autor, no Rio de Janeiro o lazer, como fato social, existiu antes da generalização dos usos do termo que viria a nomeá-lo.

Na São Paulo do século XIX (1828-1889), apesar de nomeado de outro modo, também podemos encontrar lazer (SANTOS, 2017). Ainda que não fosse o objetivo da autora comparar, é possível perceber que os divertimentos paulistanos possuíam sentidos, cumpriam funções e reuniam um conjunto de práticas culturais muito próximas, senão idênticas, às do moderno conceito de lazer - entendida a modernidade aqui, como sinônimo de industrialização. Portanto, a inexpressividade do uso da palavra lazer em tal contexto (SANTOS, 2017, p. 138), não é suficiente para afirmar que o fato social não existia. É preciso investigar o fenômeno, procurar por seu significado e não apenas pelo seu nome.

Deste modo, não se trata de negligenciar a importância do nome, mas sim de atentar para o fato de que ele, sozinho, não é indicativo da inauguração de um fato social novo, de suas mudanças, de seu desaparecimento, de sua inexistência ou de seu significado. Fica aí evidenciada, tanto por Koselleck (2006) quanto por Bloch (2001), que sem o saber viria a dialogar com a história conceitual, a insuficiência das palavras, e da etimologia das palavras, tão utilizada nos estudos do lazer, para a compreensão e o delineamento de um conceito.

Nesse sentido, a história conceitual oferece importante contribuição aos estudos do lazer, pois revela a importância da semântica histórica, da compreensão do sentido histórico do conceito, que não prescinde a dimensão linguística, mas a ultrapassa, e se dá também a partir da história social, pois "Todo conceito é não apenas efetivo 
enquanto fenômeno linguístico; ele é também imediatamente indicativo de algo que se situa para além da língua.” (KOSELLECK, 1992, p. 3). Eles possuem uma capacidade semântica superior à das meras palavras, pois articulam-se ao contexto que os produziu e sobre os quais eles podem atuar, e o tornam inteligível (KOSELLECK, 2006a, p. 98). Assim, compreender um conceito é também compreender o contexto que o produziu e sobre o qual ele atuou.

Os conceitos são, portanto, históricos e precisam ser historicizados. Eles dizem de uma determinada sociedade e, deste modo, não são universais. Por outro lado, eles podem permanecer na longa duração com modificações de sentido ou de denominação, que são indicativos das mudanças do contexto em que eles estão colocados. O que Koselleck (2006) propõe é a investigação do uso que os protagonistas de um tempo e de um espaço específicos deram às palavras, nos permitindo assim, evitar anacronismos, pois saberemos a justa medida das diferenças e semelhanças entre conceitos de ontem e de hoje.

Não se trata de definir o conceito a priori, mas sim de reconstituir uma mostra de seus significados em um dado tempo e lugar, de reconstituir os usos do conceito pelos atores de um determinado contexto (SEBASTÍAN, 2009, p. 18). Assim, saberemos se podemos ou não usar o conceito atual, com seus significados, quando nos referirmos a um determinado passado. Esse método nos permite tanto traduzir usos linguísticos passados de modo a torna-los inteligíveis nas investigações contemporâneas, já que nos permite fixa-los a partir da linguagem atual, como verificar a capacidade de rendimento de conceitos científicos atuais (KOSELLECK, 2006a, p. 116). São exatamente estas algumas das necessidades dos estudos do lazer desde algum tempo (REIS, 
CAVICHIOLLI, STAREPRAVO, 2009; MELO, 2013; MELO, 2011; MELO, 2009; DIAS, 2013; SANTOS, 2017; SANTOS, 2009).

Assim, a história conceitual é um importante procedimento que permite tanto a análise de fatos cuja denominação nos foi herdada, pois eles já foram linguisticamente articulados, e, por isso, podem estar nomeadamente presentes nas fontes, quanto a análise de fatos que não foram linguisticamente articulados no passado, e que, portanto, não estarão nomeadamente presentes nas fontes, mas que a partir dos vestígios históricos podem ser recuperados e fixados por categorias científicas definidas no presente. É o percurso que inclui a cunhagem de um termo, ou a ressignificação de um termo já existente, e os usos a ele atribuídos que constitui um conceito e que devem ser investigados.

Deste modo, o estudo diacrônico dos usos e significados de palavras como divertimento, recreação, passatempo, diversão, ócio, lazer pode oferecer contribuições para a compreensão do lazer e do divertimento, pode esclarecer se eles se referem a um mesmo fato social com variações temporais, ou se referem a fatos sociais distintos. Estudos dessa natureza nos permitirão conhecer se houve uma transição conceitual, ou a nomeação de um mesmo fato por outro termo, além de possibilitarem a verificação da validade e da utilidade do conceito analítico de lazer. O que evidencia a relevância da realização de uma história do conceito de lazer no Brasil na longa duração.

Uma das orientações metodológicas de Koselleck (2006, p. 113), diz que não apenas os usos das palavras pertencentes ao campo semântico do conceito em questão devem ser investigados, mas também os seus antônimos, pois é esse procedimento que nos permitirá conhecer os antagonismos e oposições, bem como as intersecções entre os significados dos termos. Investigar, por exemplo, os usos da palavra trabalho pode nos 
permitir compreender melhor suas relações com o lazer, suas áreas de convergência e divergência no que se refere aos significados, à função e à estrutura de sentimento.

Assim, a história conceitual nos permite saber "a partir de quando os conceitos passam a poder ser empregados de forma tão rigorosa como indicadores de transformações políticas e sociais de profundidade histórica". "Isso significa que ela deve registrar as diferentes designações para os fatos (idênticos?), de forma que lhe seja possível explicar o processo de cunhagem dessas designações em conceito." (SEBASTÍAN, 2009, p. 101 e 111, respectivamente).

A história conceitual cumpre uma função específica, de reconstituir o conceito histórico, de elaborá-lo, tornando-o inteligível no presente, mas a ultrapassa, pois serve também à história social. A constituição de um conceito, que inclui mudanças e permanências, pode indicar permanências estruturais na realidade social (PEREIRA, 2005, p. 49). Sobre isso Koselleck (1992, p. 7) nos diz:

[...] da mesma palavra um novo conceito [pode ser] forjado, e portanto ele é único a partir de uma nova situação histórica que não só engendra essa nova formulação conceitual, como também poderá se tornar através dela inteligível.

Deste modo, como os momentos históricos engendram seus próprios conceitos, estes tornam possível a compreensão dos contextos que os constituíram. Eles nos permitem acessar e compreender os diferentes momentos históricos, captando permanências e rupturas, continuidades e descontinuidades.

Assim, a história conceitual pode nos permitir compreender melhor o lazer ao longo do tempo, possibilitando-nos conhecer sua variação temporal e, assim, defini-lo melhor nas investigações contemporâneas que realizamos do passado. Ela nos permitirá, ainda, verificar a capacidade heurística do atual conceito científico de lazer, analisando o seu alcance temporal e a validade de suas balizas. 


\section{Últimas Palavras}

O campo de estudos do lazer reclama há algum tempo, por melhores compreensões históricas e conceituais do fenômeno a que se dedica. No sentido de tentar contribuir para a construção de tais compreensões, apresentei nesse texto alguns subsídios teórico-metodológicos da histórica conceitual (KOSELLECK, 2006). Tal proposta evidencia alguns equívocos que tem sido cometidos, pelos estudiosos do campo do lazer, bem como apresenta possibilidades de superá-los.

Essas possibilidades, no entanto, estão ligadas a um determinado modo de compreender a história e o fazer historiográfico. Elas indicam como equivocados o apego aos símbolos linguísticos que denominam os fenômenos, bem como a utilização da etimologia das palavras para esclarecer conceitualmente um fenômeno. Indicam o trabalho empírico, através da crítica das fontes, para decifrar os conceitos nelas contidos. O que não exclui ou desconsidera a importância das palavras, apenas a supera, pois o que deve ser buscado é o conteúdo das mesmas, os usos delas feitos pelos sujeitos de um dado tempo e lugar. Deste modo, os caminhos teórico-metodológicos propostos por Koselleck (2006) podem contribuir para a superação de algumas questões e problemas do campo de estudos do lazer.

\section{REFERÊNCIAS}

ARAÚJO, Melvina Afra Mendes de. O vai e vem dos conceitos: de categoria analítica a categoria nativa ou vice versa. O caso do sincretismo. Debates do NER, Porto Alegre, v. 1, n. 19, 2011. Disponível em: http://seer.ufrgs.br/debatesdoner/article/view/19025. Acesso em: 23 set. 2017.

BLOCH, Marc. Apologia da história ou o ofício de historiador. Rio de Janeiro: Jorge Zahar, 2001.

BURKE, Peter. The invention of leisure in early modern Europe. Past and Present, $n$. 146, p. 136-150, Feb., 1995. 
CASTRO, Eduardo Viveiros de. O nativo relativo. Mana, Rio de Janeiro, v. 8, n. 1, p. 113-148, abr. 2002. Disponível em:

http://www.scielo.br/scielo.php?script=sci_arttext\&pid=S0104-93132002000100005. Acesso em: 02 ago. 2017.

CHALHOUB, Sidney. Trabalho, lar e botequim: o cotidiano dos trabalhadores no Rio de Janeiro da belle époque. $2^{a}$ edição. Campinas: Editora da Unicamp, 2001.

DIAS, Cleber. Emergência histórica do lazer no Brasil. In: ISAYAMA, Helder Ferreira; OLIVEIRA, Marcus Aurélio Taborda de. (Org.). Produção de conhecimento em estudos do lazer. Belo Horizonte: Ed. da UFMG, 2014, p. 49-64

DIAS, Cleber. Epopeias em dias de prazer: uma história do lazer na natureza (17791838). Goiânia: Editora UFG, 2013.

DIAS, Cleber. Teorias do Lazer e modernidade: problemas e definições. Licere, Belo Horizonte, v.12, n.3, set. 2009.

DUMAZEDIER, Joffre. Sociologia empírica do lazer. São Paulo: Perspectiva / SESC, 1999.

GOMES, Christianne Luce; MELO, Victor Andrade de. Lazer no Brasil: trajetória de estudos, possibilidades de pesquisa. Movimento, vol. 9, núm. 1, Janeiro-abril, 2003. Disponível em: http://www.seer.ufrgs.br/Movimento/article/viewFile/2661/1294. Acesso em: 02 jul. 2017.

MARCASSA, L. A invenção do lazer: educação, cultura e tempo livre na cidade de São Paulo (1888 - 1935). 2002. 204 f. Dissertação (Mestrado em Educação) Faculdade de Educação, Universidade Federal de Goiás, Goiânia, 2002.

MARCELLINO, Nelson Carvalho. Lazer e humanização. Campinas: Papirus, 1983.

MASCARENHAS, F. Entre o ócio e o negócio: teses acerca da anatomia do lazer. 2005, 307f. Tese (Doutorado em Educação Física) - Faculdade de Educação Física, Universidade Estadual de Campinas, Campinas, 2005.

MELO, Victor Andrade de. Sobre o conceito de lazer. In: Sinais Sociais, Rio de Janeiro, v. 8, n. 23, set-dez, 2013.

O lazer (ou a diversão) e os estudos históricos. In: ISAYAMA, Hélder, SILVA, Sílvio Ricardo. Estudos do lazer: um panorama. Rio de Janeiro: Apicuri, 2011. Esporte e lazer: conceitos. Rio de Janeiro: Apicuri/Faperj, 2010.

MELO, Victor A; ALVES JUNIOR, Edmundo D. Introdução ao lazer. Barueri: Manole, 2003.

KOSELLECK, Reinhart. Futuro passado: contribuição à semântica dos tempos históricos. Rio de Janeiro: Contraponto/Editora PUC-Rio, 2006a. 
. Uma história dos conceitos: problemas teóricos e práticos. Estudos Históricos, Rio de Janeiro, v. 5, n. 10, p. 134-146, 1992. Disponível em: $<$ http://www.cpdoc.fgv.br/revista/arq/101.pdf>. Acesso em: 29 nov. 2013.

JASMIN, Marcelo Gantus; FERES JÚNIOR, João. História dos conceitos: dois momentos de um encontro intelectual. In: JASMIN, Marcelo Gantus; FERES JÚNIOR, João (orgs.). História dos conceitos: debates e perspectivas. Rio de Janeiro: Editora PUC-Rio/Edições Loyola/Iuperj, 2006.

PEREIRA, Luísa Rauter. "Substituir a revolução dos homens pela revolução do tempo" - Uma história do conceito de povo no Brasil: revolução e historicização da linguagem política (1750-1870). 2011. Tese (Doutorado em Ciência Política). Rio de Janeiro: Universidade do Estado do Rio de Janeiro, 2011.

O Conceito de Soberania: dilemas e conflitos na construção e crise do Estado Imperial Brasileiro (1750-1870). Intellèctus, Rio de Janeiro, ano IX, n. 2, 2010.

A história e o diálogo que somos: a historiografia de Reinhart Koselleck e a hermenêutica de Hans-Georg Gadamer. Dissertação (Mestrado em História Social) PUC-Rio, Rio de Janeiro, 2005.

REIS, Leoncio; CAVICHIOLLI, Fernando; STAREPRAVO, Fernando. A ocorrência histórica do lazer: reflexões a partir da perspectiva configuracional. Revista Brasileira de Ciências do Esporte, Campinas, vol. 30, n. 3, 2009. Disponível em: http://www.revista.cbce.org.br/index.php/RBCE/article/view/248. Acesso em: 14 jul. 2017.

SANTOS, Flávia da Cruz. Uma história do conceito de divertimento na São do século XIX (1828-1889). 2017. Tese (Doutorado em Estudos do Lazer). Belo Horizonte: Universidade Federal de Minas Gerais.

. Lazer no Brasil: primeiras aproximações a uma outra história. In: MONTEIRO, Mônica; DIAS, Cleber (orgs.). Lazer e periferia: um olhar a partir das margens. Rio de Janeiro: Instituto Usina Social, 2009.

SEBASTIÁN, Javier Fernández. Introdução: Hacia una história atlántica de los conceitos políticos. In: (Org.) Diccionario político y social del mundo iberoamericano: la era de las revoluciones 1750-1850, vol. I. Madrid: Centro de Estudios Políticos y Constitucionales, Fundación Carolina; Soc. Estatal de Conmemoraciones Cult, 2009.

. Trocando em miúdos. Revista de História da Biblioteca Nacional, Rio de Janeiro, ano 9, n. 98, p. 52-57, novembro 2013. Entrevista concedida a Bruno Garcia e Cristiane Nascimento.

THOMPSON, Edward Palmer. Tempo, disciplina de trabalho e o capitalismo industrial. In: _ Costumes em comum: estudos sobre a cultura popular tradicional. São Paulo: Companhia das Letras, 1998. 


\section{Endereço da autora:}

Flávia da Cruz Santos

Universidade Federal de Juiz de Fora

Rua José Lourenço Kelmer, s/n

Juiz de Fora - MG - 36/036-330

Endereço eletrônico: flacruz.santos@gmail.com 